J. Lake Sci. (湖泊科学), 2015, 27(1): 44-49

http: //www. jlakes.org. E-mail : jlakes@niglas.ac.cn

(C) 2015 by Journal of Lake Sciences

\title{
流速对浮游藻类生长和种群变化影响的模拟试验“
}

\author{
李飞鹏 ${ }^{1}$, 高 雅 $^{2}$, 张海平 $^{1 * *}$, 肖宜华 ${ }^{1}$, 陈 玲 $^{1}$ \\ (1: 同济大学环境科学与工程学院,上海 200092) \\ (2: 同济大学建筑设计研究院 (集团)有限公司,上海 200092)
}

\begin{abstract}
摘 要: 采集夏季崇明岛中心湖原水, 在环形有机玻璃水槽开展了不同流速对浮游藻类生长和种群变化影响的研究. 相 对于静止水槽, 实验前期不同的流速条件均对浮游藻类的生长产生了一定的抑制作用, 实验后期浮游藻类叶绿素 a 含量 均稳定在一定水平, 且流动水槽中叶绿素 $\mathrm{a}$ 含量略大于静止水槽, 这可能与静止围隔中出现大量枝角类浮游动物有关, 而 流动条件则抑制了浮游动物的生长, 减轻了对浮游藻类的捕食压力. 水体流动导致了浮游藻类种群的变化, 蓝藻的迅速 消失、绿藻和硅藻形成生长优势是主要特征, 表明持续的流动条件是导致浮游植物种属减少和群落结构变化的直接原 因. 该研究可为调水引流在河道、湖泊和水库中的富营养化控制和水华防治提供基础依据.
\end{abstract}

关键词 : 流速;浮游藻类;种群变化;模拟试验

\section{Simulation experiment on the effect of flow velocity on phytoplankton growth and compo- sition}

LI Feipeng ${ }^{1}$, GAO Ya ${ }^{2}$, ZHANG Haiping ${ }^{1}$, XIAO Yihua ${ }^{1} \&$ CHEN Ling $^{1}$

(1: College of Environmental Science and Engineering, Tongji University, Shanghai 200092, P. R. China)

(2: Tongji Architectural Design (Group) Co. , Ltd., Shanghai 200092, P. R. China)

\begin{abstract}
An experimental simulation study was conducted using surface water from Zhongxinhu Lake of Chongming Island in oval plexiglass enclosures. The object of the study was to investigate the effect of flow velocity on phytoplankton growth and composition dynamics. Both flow conditions had inhibition effects on phytoplankton biomass in early experiment compared with the still enclosure and in late experiment the phytoplankton biomass stabilized in a certain level in all enclosures. Moreover, a higher Chl. a concentration was found in both flow enclosures in the late experiment, implying that numerous Cladocera zooplankton occurred in the still enclosure might be the reason that in flow conditions the turbulent flows inhibited the growth of zooplankton and reduced the predation pressure of phytoplankton. The turbulent flow also resulted in the changes of phytoplankton composition with the feature of the rapid disappearance of blue-green algae and the domination of green algae and diatoms. The result indicated that the continuous flow may directly caused the reducing species and composition dynamics of phytoplankton. The study can provide basis of the application of water division in eutrophication management and algae bloom prevention of rivers, lakes and reservoirs.
\end{abstract}

Keywords: Flow velocity; phytoplankton; species dynamics; simulation experiment

流速是水动力条件中最基本、最直观的参数, 对浮游植物的生长和繁殖具有十分重要的影响, 不仅影响 水体中能量和营养盐的分配、溶解氧水平、沉积物特性等, 而且能够对水生生物的生理活动产生直接的影 响. 天然河流、湖泊和水库中, 有关流速与浮游藻类生物量统计关系的研究也常见报道, 流速、流量等水动力 条件已经成为浮游植物生长繁殖、群落更替和诱发水华现象的重要驱动因子 ${ }^{[1-2]}$. 对浮游植物个体而言, 每 种生命体对其生存的流场环境都有特定的要求,当条件改变时,生命体都会表现出自由、逃离和失控 3 种状 态 ${ }^{[3]}$. 因此, 通过研究浮游植物个体在不同水动力条件下的生命规律, 局部改变有害藻类生存的流场, 达到

* 国家自然科学基金项目 (51379146,51409190) 和中国博士后科学基金项目 (2013 M531218) 联合资助. 2014 - $01-$ 24 收稿;2014-04-15 收修改稿. 李飞鹏(1983～), 男,博士;E-mail:lifeipeng@ tongji. edu. cn.

** 通信作者;E-mail:hpzhang@ tongji. edu.cn. 
抑制水华暴发的目的,具有十分重要的意义.

由于自然水体中藻类生长的影响因素较为复杂,流速效应经常被其他各种因素所掩盖而导致研究结论 不明确. 室内模拟实验能够在排除其它因素影响的情况下较为精细地反映流速与浮游植物之间的关系 ${ }^{[4-6]}$, 许多研究者通过研究流速对单一藻种或者混合藻种的影响, 认为存在一定的临界流速, 当流速大于或者小 于临界流速时, 浮游植物的生长速率都会减缓 ${ }^{[7]}$. 但受空间和时间尺度限制, 其研究结论缺乏普遍性, 结果 差异性较大, 仍需大量更大尺度的研究 ${ }^{[8-10]}$. 朱宜平等 ${ }^{[11]}$ 、i 等 $^{[12]}$ 通过野外围隔实验, 发现 $0.03 \sim 0.30 \mathrm{~m} / \mathrm{s}$ 的流速均对叶绿素 $\mathrm{a}$ 浓度产生抑制作用,并且显著降低藻类丰度; 但受底泥扰动和降雨等因素影响,再加上 水动力产生的剪切力极大地促进了水绵的营养生殖, 流速效应同样受到一定程度的掩盖. 因此, 本研究在野 外模拟实验的基础上,采用较大尺度的有机玻璃水槽来模拟夏季富营养水体中流速对浮游藻类生长和种群 变化的影响,以期准确反映流速对浮游植物生长的抑制效果和种群变化规律.

\section{1 材料与方法}

中心湖位于上海市崇明县坚新镇前卫村,该水体毗邻同济大学长江水环境教育部重点实验室崇明水环 境研究中心, 是由 5 条相互贯通的河段组成的封闭水域,面积约 $52000 \mathrm{~m}^{2}$,水深 $1.0 \sim 1.3 \mathrm{~m}$, 全湖总氮 ( TN ) 浓度为 $0.53 \sim 4.14 \mathrm{mg} / \mathrm{L}$, 总磷 ( TP) 浓度为 $0.056 \sim 0.750 \mathrm{mg} / \mathrm{L}$. 该水体封闭性较好且具有相对简单的生态 系统,十分便于野外密集观测和现场实验研究. 具体信息可参考文献 [13].

实验装置采用 3 个环形有机玻璃水槽, 如图 1 所示, 四周为透明有机玻璃板, 底部为加厚 PVC 板, 高 $1.3 \mathrm{~m}$, 置于崇明水环境研究中心大厅内, 避开了底泥扰动起浮和降雨带来的影响. 从早上至上午 $10: 30$ 左右 装置能接受阳光照射,白天时段通过日光灯提供光照条件, 日光灯于早上 $6: 00$ 开启,晚上 $18: 00$ 关闭. 实验 用水为中心湖原水,于 2010 年 8 月 13 日取水约 $480 \mathrm{~L}$ 置于装置内,用 2 种不同型号潜水洜 ( 堵住增氧口) 推 流, 其中一个装置保持静止, 作为对比参照. 3 个装置分别标记为 $\mathrm{S} 0 、 \mathrm{~S} 1$ 和 $\mathrm{S} 2$, 对应的平均驱动流速分别为 $0 、 0.06$ 和 $0.10 \mathrm{~m} / \mathrm{s}$, 实验周期约为 $13 \mathrm{~d}$. 同时实验中还采集中心湖西部的 1 个监测点 (W2) 作为对照. 实验 期间向 3 个装置中分别加人 $200 \mathrm{ml}\left(15 \mathrm{~g} / \mathrm{L}\right.$ 的 $\mathrm{NaNO}_{3}$ 和 $3 \mathrm{~g} / \mathrm{L}$ 的 $\left.\mathrm{KH}_{2} \mathrm{PO}_{4}\right)$ 营养盐溶液,隔天测 1 次营养盐浓 度, 保证装置中氮、磷营养盐浓度维持在高富营养水平 ( TN 浓度大于 $2 \mathrm{mg} / \mathrm{L}$ 和 TP 浓度大于 $0.2 \mathrm{mg} / \mathrm{L}$ ), 自 8 月 15 日开始,每天早上 $(8: 00)$ 和晚上 $(17: 00)$ 分别监测 1 次,记录水温、溶解氧 (DO)、pH、电导率等,并采 样测定叶绿素 a (Chl. a) 浓度和蓝藻、绿藻、硅藻的生物量比例.
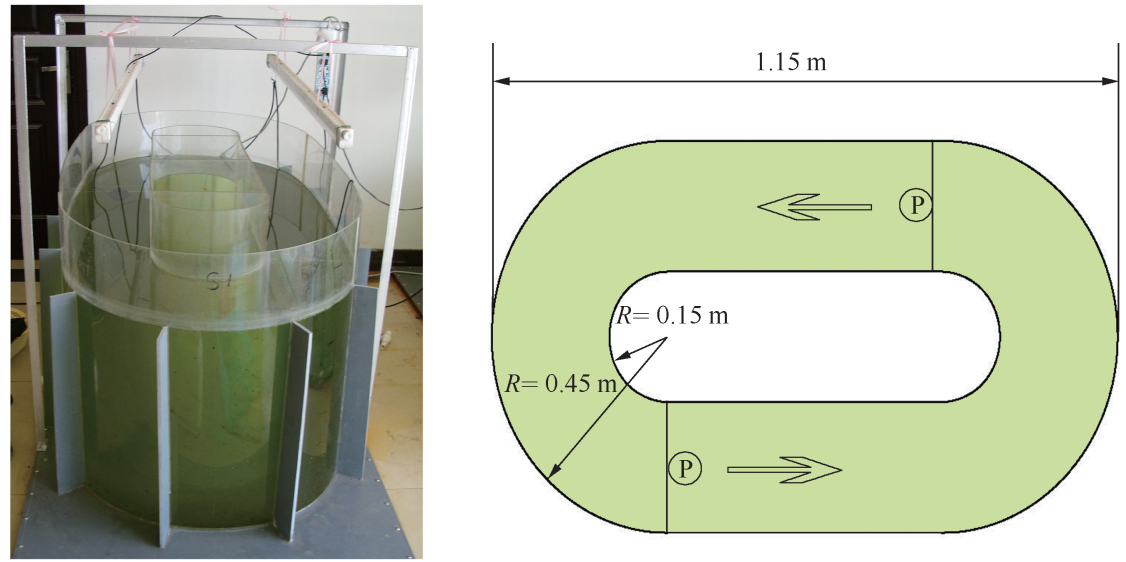

图 1 围隔实验装置及示意图

Fig. 1 Enclosure experimental apparatus and its diagram

流速采用便携式智能流速仪 (LGY-II 型, 南京水利科学研究院) 测定. 现场通过便携式水质分析仪 ( Hq40d, HACH, 美国) 测定并记录 DO 、 $\mathrm{pH}$ 值、电导率、水温等指标, 采用散射光浊度仪 (WGZ-1 A 系列, 上海 昕瑞仪器仪表有限公司) 测定样品浊度. 参照国家环保部推荐的标准方法测定铵态氮 $\left(\mathrm{NH}_{4}^{+}-\mathrm{N}\right)$ 、硝态氮 
$\left(\mathrm{NO}_{3}^{-}-\mathrm{N}\right)$ 、溶解性总氮 $(\mathrm{DTN}) 、 \mathrm{TN} 、$ 磷酸盐 $\left(\mathrm{PO}_{4}^{3-}-\mathrm{P}\right)$ 、溶解性总磷 $(\mathrm{DTP}) 、 \mathrm{TP}$ 等营养盐指标的浓度.

\section{2 结果与讨论}

\section{1 物化因素分析}

实验期间不同流速下水温波动较小, 在 $28.1 \sim 31.4^{\circ} \mathrm{C}$ 之间, 平均水温为 $29.6^{\circ} \mathrm{C}$, 在显著性水平 $P=0.05$ 下各装置水温无显著性差异. 在没有底泥干扰情况下, 各装置浊度亦无显著性差异, 除第 $1 \mathrm{~d}(\mathrm{D} 1)$ 浊度较高 (约为 $15.0 \mathrm{NTU}$ ) 外, 之后均保持较低的水平, 大致在 $2.2 \sim 4.5 \mathrm{NTU}$ 范围内 (表 1). 由于添加了营养盐, 保证 了各装置中营养盐保持在较高水平, 平均浓度分别为 $\mathrm{NH}_{4}^{+}-\mathrm{N}: 0.483 \mathrm{mg} / \mathrm{L} 、 \mathrm{DTN}: 5.247 \mathrm{mg} / \mathrm{L} 、 \mathrm{TN}: 5.821 \mathrm{mg} / \mathrm{L}$ 、 DTP:0. $279 \mathrm{mg} / \mathrm{L} 、 \mathrm{TP}: 0.361 \mathrm{mg} / \mathrm{L}$, TN 和 TP 浓度约为同期中心湖浓度的两倍, 各装置营养盐浓度变化无显 著性差异. 这就表明, 在 S0、S1 和 S2 运行下, 由于水温、营养盐差异引起的相关参数差别不明显. 3 个装置运 行过程中, $\mathrm{pH}$ 和电导率变化范围较小, 水体 $\mathrm{pH}$ 值基本维持在弱碱性, 在 $7.93 \sim 8.78$ 范围内变化, 电导率基 本在 $1066 \sim 1151 \mu \mathrm{S} / \mathrm{cm}$ 范围内波动, 流动装置中水体电导率略高于静止装置.

表 1 实验期间不同流速下水温、 $\mathrm{pH}$ 、电导率和浊度的日变化趋势

Tab. 1 Daily variations of water temperature, $\mathrm{pH}$, conductivity and turbidity under different flow conditions

\begin{tabular}{|c|c|c|c|c|c|c|c|c|c|c|c|c|}
\hline \multirow{2}{*}{ 时间 } & \multicolumn{3}{|c|}{ 水温 $/{ }^{\circ} \mathrm{C}$} & \multicolumn{3}{|c|}{$\mathrm{pH}$} & \multicolumn{3}{|c|}{ 电导率/ $(\mu \mathrm{S} / \mathrm{cm})$} & \multicolumn{3}{|c|}{ 浊度/NTU } \\
\hline & S0 & S1 & S2 & So & S1 & S2 & S0 & S1 & S2 & S0 & S1 & S2 \\
\hline D1 & 31.0 & 31.2 & 31.4 & 8.01 & 8.17 & 8.18 & 1083 & 1125 & 1126 & 14.6 & 17.9 & 18.3 \\
\hline D2 & 29.7 & 30.4 & 30.6 & 8.06 & 8.23 & 8.32 & 1128 & 1135 & 1134 & 6.5 & 9.8 & 11.0 \\
\hline D3 & 29.6 & 29.8 & 30.2 & 8.72 & 8.71 & 8.78 & 1088 & 1140 & 1140 & 4.9 & 6.7 & 7.2 \\
\hline D4 & 28.1 & 28.7 & 29.1 & 8.41 & 8.33 & 8.39 & 1117 & 1149 & 1147 & 4.7 & 5.6 & 6.0 \\
\hline D5 & 29.0 & 29.1 & 29.5 & 8.32 & 8.40 & 8.34 & 1094 & 1137 & 1135 & 4.5 & 3.8 & 4.1 \\
\hline D6 & 29.1 & 29.1 & 29.3 & 7.98 & 7.93 & 8.08 & 1114 & 1147 & 1144 & 4.5 & 3.2 & 4.0 \\
\hline D7 & 30.0 & 29.2 & 29.5 & 8.14 & 8.35 & 8.43 & 1117 & 1151 & 1150 & 3.7 & 4.2 & 4. 1 \\
\hline D8 & 28.3 & 29.0 & 29.3 & 8.19 & 8.40 & 8.46 & 1103 & 1143 & 1143 & 2.6 & 3.1 & 3.5 \\
\hline D9 & 29.1 & 29.2 & 29.6 & 8.16 & 8.43 & 8.50 & 1096 & 1121 & 1118 & 2.2 & 3.4 & 4.3 \\
\hline D10 & 28.8 & 29.5 & 29.8 & 7.99 & 8.32 & 8.38 & 1066 & 1110 & 1116 & 2.4 & 3.9 & 4.6 \\
\hline D11 & 29.4 & 29.6 & 30.0 & 8.02 & 8.35 & 8.43 & 1103 & 1133 & 1124 & 2.6 & 3.0 & 4.0 \\
\hline D12 & 29.6 & 29.6 & 30.0 & 8.05 & 8.44 & 8.54 & 1090 & 1121 & 1125 & 2.5 & 2.8 & 3.8 \\
\hline D13 & 29.8 & 29.8 & 30.1 & 8.10 & 8.25 & 8.40 & 1098 & 1120 & 1122 & 2.4 & 3.1 & 4.2 \\
\hline
\end{tabular}

水体流动对装置内 DO 影响较大, DO 的日变化如图 2a 所示. S1 和 S2 水体中 DO 浓度在前 $2 \mathrm{~d}$ 发生骤 降,自第 $3 \mathrm{~d}$ 开始受水体流动影响逐步变大,第 $5 \mathrm{~d}$ 开始基本保持稳定. S2 中 DO 浓度略高于 $\mathrm{S} 1$, 两者稳定后 的平均 DO 浓度分别为 7.3 和 $7.7 \mathrm{mg} / \mathrm{L}$, 显著高于静止水槽 ( DO 平均浓度为 $4.5 \mathrm{mg} / \mathrm{L}$ ). 静止装置中 DO 变 化波动明显, 可能受浮游植物生长影响较大.

\section{2 流速对浮游藻类生长的影响}

Chl. a 浓度变化趋势如图 $2 \mathrm{~b}$ 所示, 初始 Chl. a 浓度为 $44.22 \mu \mathrm{g} / \mathrm{L}$. 浮游藻类从自然水体移到小尺度的水 槽, 必然要经历一个适应的过程. 实验最初阶段, 在 0.06 和 $0.10 \mathrm{~m} / \mathrm{s}$ 流速下, Chl. a 浓度在第 $2 \mathrm{~d}$ 均增加了 约 1.2 倍, 静止水槽中藻类的增长并不明显, 这是由于水流加速了营养盐向藻细胞的扩散, 显著刺激了浮游 藻类生长, 此时水流引起的营养盐向藻细胞的扩散作用为控制因素. 流速对浮游植物的抑制效果在第 $3 \sim 8 \mathrm{~d}$ 表现明显, 静止围隔中 Chl. a 浓度在实验开始前 $3 \mathrm{~d}$ 有所降低, 之后出现大幅升高, 于第 $6 \mathrm{~d}$ 下午达到最高值 $55.24 \mu \mathrm{g} / \mathrm{L}$, 随后逐渐降低至 $10 \mu \mathrm{g} / \mathrm{L}$ 左右; 两种流速下浮游藻类的生长规律相对一致, Chl. a 浓度差异不明 显, 自第 $3 \mathrm{~d}$ 开始出现明显下降, 至第 $6 \mathrm{~d}$ 和第 $7 \mathrm{~d}$ 降低至 $10 \mu \mathrm{g} / \mathrm{L}$, 随后小幅升高, 稳定在 $20 \sim 30 \mu \mathrm{g} / \mathrm{L}$ 左 右. 实验第 $8 \mathrm{~d}$ 以后, 静止装置中 Chl. a 浓度出现明显下降, 这与装置中出现大量的浮游动物关系密切. 镜检 结果发现, 此时装置中水体清澈透明, 藻细胞数量很少, 枝角类浮游动物增多, 平均密度超过 $80 \mathrm{ind}$. / L, 远大 于 $\mathrm{S} 1$ 和 $\mathrm{S} 2$ 中的平均密度 20 ind. /L. 朱宜平等 ${ }^{[11]}$ 在流速为 $0.002 \mathrm{~m} / \mathrm{s}$ 的野外围隔实验条件下, 发现水体中 
有大量的枝角类动物生长, 主要种类为秀体溞属 (Diaphanosoma) 和溞属 (Daphnia), 能够将浮游藻类捕食殆 尽. 陈伟民等 ${ }^{[10]}$ 认为相对于大水流状态, 在静止状态和微小流动状态下, 枝角类种类和数量会明显增多, 且以 大体型种类为主, 常以浮游单细胞藻类、有机碎屑等为食, 受到这些浮游甲壳动物的滤食, 浮游藻类的数量和 生物量将大幅降低. 在 0.06 和 $0.10 \mathrm{~m} / \mathrm{s}$ 流速下,Chl. a 浓度除在后期出现了小幅度升高外, 基本保持稳定, 这 可能是由于在流动条件下, 流速抑制了浮游动物的生长, 减小了浮游藻类的被捕食压力, 促进了流动系统中生 态系统的相对稳定. 从生物量的角度计算, 在这种尺度的实验条件下, 流速对浮游藻类生长的相对抑制率约可 达到 50\% . 根据潜水洜自身带来的剪切效应对藻类细胞的影响,估算由此带来的抑制率在 $10 \%$ 左右 ${ }^{[12]}$.
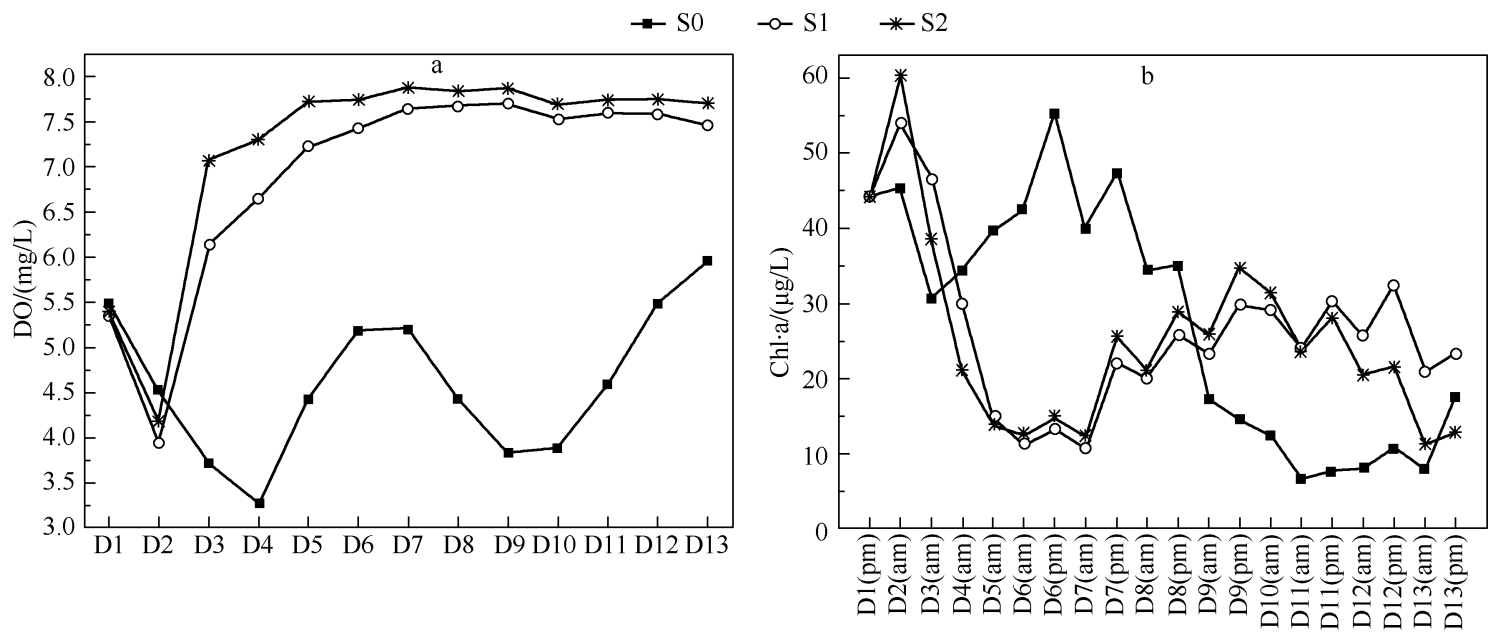

图 2 无底泥围隔中不同流速下 DO $(\mathrm{a})$ 和 Chl. a(b) 的变化趋势

Fig. 2 Daily variations of DO values (a) and Chl. a concentrations (b) under different

flow conditions in enclosures

流速对水体 DO 浓度的影响是本研究的重要影响因素. 实验过程中堵住潜水泵的增氧口, 使得潜水泵的 主要功能为制造水流. 前 $2 \mathrm{~d}$ 流动水槽中 DO 浓度有一定的骤降, 这与第 $2 \mathrm{~d}$ 浮游植物的骤增进而会消耗大 量 DO 有关. 在水流效应下,水层之间的摚动形成较强的扩散梯度,将造成大气中 DO 的快速补充,因此自第 $3 \mathrm{~d}$ 开始 DO 浓度迅速上升且基本保持稳定,这说明水体流动引起的 DO 浓度增加起主导作用,同时也说明 水体中浮游藻类的光合作用能力可能受到了水流的影响; 静止水槽中, DO 浓度呈 $\mathrm{W}$ 形波动, 与该水槽中浮 游藻类的 Chl. a 浓度变化趋势基本一致,DO 的上升与降低略微迟滞于 Chl. a 浓度的变化,这是由于静止条 件下 DO 的扩散较慢. 由于静止水体中 DO 浓度主要受浮游藻类光合作用产氧的影响, 同时由于有机物、浮 游动物等耗氧, DO 浓度经常处于较低水平,但静止水体中 Chl. a 浓度在第 $3 \sim 8 \mathrm{~d}$ 显著高于流动水体,说明 流动水槽中流速对浮游藻类的生长产生的抑制作用占据主导, $\mathrm{DO}$ 对浮游藻类生长的作用弱于流速的作用.

\section{3 流速对浮游藻类种群变化的影响}

静止装置 $(S 0)$ 和流动装置 $(S 1$ 和 S2) 中浮游植物种群变化差异明显, 优势种属变化如表 2 所示. 运行 前, 各装置优势藻种相同, 主要为蓝藻门的微囊藻属、绿藻门中的纤维藻属和硅藻中的小环藻属. S1 和 S2 形 成持续流动后, 第 5 天即观察到微囊藻消失, 且浮游藻种类越来越少, 最后以绿藻为主, 而静止围隔中, 微囊 藻直到第 $10 \mathrm{~d}$ 一直存在,这与每日进行的 Phyto-PAM 检测的种属变化结果比较一致(图 3).

在中心湖 (W2) 监测点, 前 $10 \mathrm{~d}$ 主要是蓝藻和硅藻为优势种, 平均生物量所占的比例分别为 $47.7 \%$ 和 $52.3 \%$, 后 $3 \mathrm{~d}$ 硅藻少量出现, 优势种 $99 \%$ 以上为蓝藻, 这与微囊萂的生理特性是相符的; S0 中的藻种变化 在前 $10 \mathrm{~d}$ 与 W2 相仿, 后 $3 \mathrm{~d}$ 仅存绿藻中纤维藻属, $\mathrm{S} 1$ 和 S2 中的蓝藻分别在第 $5 \mathrm{~d}$ 和第 $4 \mathrm{~d}$ 全部消失, 之后 两个装置中均以绿藻为主、硅藻为辅, 此时 S1 中绿藻和硅藻的平均生物量比例为 $77.1 \%$ 和 $22.9 \%, \mathrm{~S} 2$ 中的平 均生物量比例为 $83.7 \%$ 和 $16.3 \%$,S2 中的环境条件相对更有利于绿藻生长 (图 3). 但静止水槽中, 第 $11 \mathrm{~d}$ 开 始微囊藻很快消失. S0、S1 和 $\mathrm{S} 2$ 后期均以绿藻门中的纤维藻属为主, 这可能与浮游动物的选择性捕食有关. 
从静止状态向持续流动状态, 浮游植物种属优势种基本从蓝藻向绿藻转化, 这与国外在淡水河流 ${ }^{[14]}$ 、湖 泊 $^{[15]}$ 中的研究结论是一致的. 从生物学的意义来看, 多数蓝藻具有气囊, 能够在水体中垂直移动, 获取有利 于自身增殖的营养盐和光照条件, 较适宜在静止或弱紊动水体中生长, 而多数绿藻和硅藻自身不能够运动, 在流动或紊动的环境下反而能获得较大的增殖优势, 这也是 $\mathrm{S} 0$ 中蓝藻能够在第 $10 \mathrm{~d}$ 以后才消失而流动水 体中蓝藻在第 $4 \mathrm{~d}$ 或第 $5 \mathrm{~d}$ 即消失的主要原因. S0 中枝角类浮游动物多以单细胞藻类为食, 使得围隔装置内 以其难以受食的纤维藻属占据优势地位.

表 2 流动和静止围隔装置内浮游植物的优势种属变化*

Tab. 2 Dominant phytoplankton species variations in still enclosure and flow enclosures

\begin{tabular}{cll}
\hline 时间点 & 静止围隔 $(\mathrm{S} 0)$ & 流动围隔 $(\mathrm{S} 1$ 和 S2) \\
\hline 运行前 & 微囊藻属 (Microcystis)、纤维藻属(Ankistrodesmus)、小环藻属 (Cyclotella) $)$ & 微囊藻属、纤维藻属、小环藻属 \\
D2 & 微囊藻属、纤维藻属、直链藻属(Melosira)、小环藻属 & 微囊藻属、纤维藻属、小环藻属 \\
D5 & 微囊藻属、纤维藻属、小环藻属 & 纤维澡属、栅藻属 $($ Scenedesmus $)$ \\
D8 & 微囊藻属、小环藻属 & 纤维藻属、栅藻属 \\
D12 & 纤维藻属 & 纤维藻属 \\
\hline
\end{tabular}

* 运行前为 2010 年 8 月 10 日中心湖 (W2) 优势藻种.

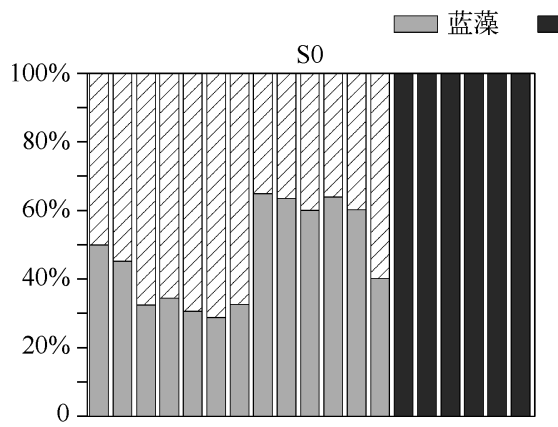

S1

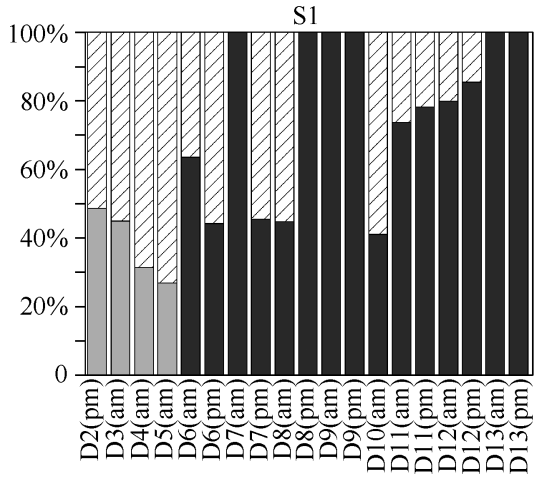

绿藻 VZ7/硅藻 W2

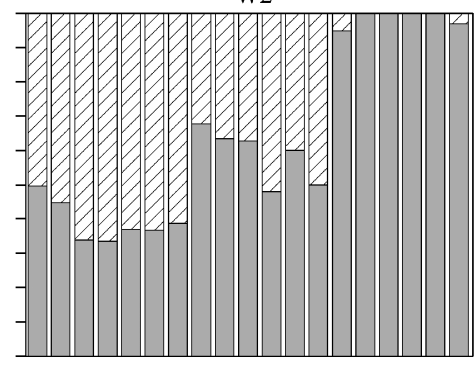

S2

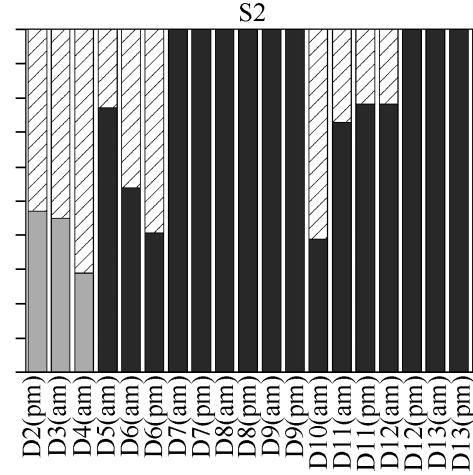

图 3 实验期间无底泥围隔装置和中心湖中蓝藻、绿藻和硅藻生物量比例变化

Fig. 3 Daily biomass variations of Cyanophyta, Chlorophyta and diatoms composition in enclosures and Zhongxinhu Lake during observation periods

水动力对浮游藻类群落演替的影响显著. Leira 等 ${ }^{[16]}$ 指出水动力强度变化是影响浮游藻类群落演替和 数量变化的重要原因. Elliott 等 ${ }^{[17]}$ 认为水动力对藻类群落演替的影响极其显著, 水动力条件会对一些浮游 藻类生长造成抑制, 同时促进其他藻类的生长. 本研究中两组实验在流动的围隔装置内均发现了浮游植物 优势藻种的显著变化, 蓝藻的迅速消失、绿藻和硅藻形成生长优势是其主要特征. Huisman 等 $^{[18]}$ 通过研究认 为, 随着水动力作用的增强, 水体 Chl. a 浓度增加受抑制, 且易下沉的绿藻和硅藻替代能垂直自由运动的蓝 
藻而成为优势种, 认为藻类对光的竞争是造成群落演替的主要原因. 本研究中采用透明的有机玻璃水槽, 底 部水体也能得到较好的光照条件. 与自然水体相比,可能排除了浮游藻类对光的竞争, 具有伪空胞的蓝藻无 需浮到水面也能获取足够光照, 因此对光的竞争可能不是引起本研究中藻类种群变化的原因. 与所在的自 然水体 W2 相比, W2 中蓝藻一直是优势种, 流动水槽 S1 和 S2 分别在第 $5 \mathrm{~d}$ 和 $4 \mathrm{~d}$ 以后蓝藻消失, 一方面说 明流速对蓝藻的抑制作用显著, 另一方面说明空间尺度的改变显著影响了浮游藻类的生存环境, 由于藻类 生理习性的差异, 不同物种对环境变化的适应速度是不同的, 因此造成了适应相对较快的藻类生长速度加 快, 而适应相对较慢的藻类生长受到抑制, 甚至在这样的环境中被淘汰. 郭蔚华等 ${ }^{[19]}$ 通过对优势藻种的分析 认为,在三峡水库不同类型的水体中,优势硅藻、绿藻、蓝藻对流速表现出多种结构的适应性,流速是影响优 势硅藻、蓝藻、绿藻组成变化的直接原因.

\section{3 结论}

1 ）实验中 0.06 和 $0.10 \mathrm{~m} / \mathrm{s}$ 的流速均对浮游藻类的生长具有明显的抑制作用,总体抑制率可达 $50 \%$ 左 右. 流速引起的 DO 浓度快速补充对浮游藻类的作用弱于实验中 0.06 和 $0.10 \mathrm{~m} / \mathrm{s}$ 流速的作用,但实验初期 流速加速营养盐向藻细胞扩散和实验后期流速对浮游动物生长的抑制作用仍会对流速效应造成较大影响.

2) 流速对浮游植物优势藻种变化影响显著. 与静止水槽相比, 流速对蓝藻的生长造成明显的抑制作用, 同时促进了绿藻的生长, 这与国外众多研究者在淡水河流和湖泊中的研究结果相一致. 流速对浮游藻类种 群变化的影响不仅表现为对光的竞争,而且与藻类对流速多种结构的适应性有关.

致谢: 本研究的野外工作得到同济大学长江水环境教育部重点实验室崇明水环境研究中心黄德发工程师和 张增胜博士的大力支持,在此表示感谢.

\section{4 参考文献}

[ 1 ] 孔繁翔,马荣华,高俊峰等.太湖蓝藻水华的预防、预测和预警的理论与实践. 湖泊科学,2009,21(3):314-328.

[2] 梁培瑜,王 烜,马芳冰. 水动力条件对水体富营养化的影响. 湖泊科学,2013,25(4) :455-462.

[3] 李大美.生态水力学. 北京:科学出版社,2006.

[ 4 ] 颜润润,逢 勇,赵 伟等. 环流型水域水动力对藻类生长的影响. 中国环境科学,2008,28(9):813-817.

[ 5 ] 黄钰玲,刘德富,陈明曦. 不同流速下水华生消的模拟. 应用生态学报,2008,19(10):2293-2298.

[6] 王婷婷,朱 伟,李 林. 不同温度下水流对铜绿微囊藻生长的影响模拟. 湖泊科学,2010,22(4):563-568.

[ 7 ] Mitrovic SM, Oliver RL, Rees C et al. Critical flow velocities for the growth and dominance of Anabaena circinalis in some turbid freshwater rivers. Freshwater Biology, 2003,48(1): 164-174.

[8] 古滨河,刘正文,李宽意等译. 湖沼学——内陆水生态系统. 北京: 高等教育出版社,2011:26-32.

[ 9 ] Long TY, Wu L, Meng GH et al. Numerical simulation for impacts of hydrodynamic conditions on algae growth in Chongqing Section of Jialing River, China. Ecological Modelling, 2011,222 (1) : 112-119.

[10] 陈伟民,陈宇炜,秦伯强等. 模拟水动力对湖泊生物群落演替的实验. 湖泊科学, 2000,12(4):343-352.

[11] 朱宜平,张海平,李飞鹏等. 水动力对浮游生物影响的围隔研究. 环境科学, 2010,31(1):69-75.

[12] Li FP, Zhang HP, Zhu YP et al. Effect of flow velocity on phytoplankton biomass and composition in a freshwater lake. Science of the Total Environment, $2013,447: 64-71$.

[13] 李飞鹏, 张海平,陈 玲. 小型封闭水体环境因子与叶绿素 $\mathrm{a}$ 的时空分布及相关性研究. 环境科学, 2013,34 (10): 3854-3861.

[14] Mitrovic SM, Chessman BC, Davie A et al. Development of blooms of Cyclotella meneghiniana and Nitzschia spp. (Bacillariophyceae) in a shallow river and estimation of effective suppression flows. Hydrobiologia, 2008,596 (1) : 173-185.

[15] Hondzo M, Warnaars TA. Coupled effects of small-scale turbulence and phytoplankton biomass in a small stratified lake. Journal of Environmental Engineering-Asce, 2008, 134(12) : 954-960.

[16] Leira M, Cantonati M. Effects of water-level fluctuations on lakes: an annotated bibliography. Hydrobiologia, 2008,613 (1) :171-184.

[17] Elliott JA, Defew L. Modelling the response of phytoplankton in a shallow lake (Loch Leven, UK) to changes in lake retention time and water temperature. Hydrobiologia, 2012,681(1):105-116.

[18] Huisman J, Sharples J, Stroom JM et al. Changes in turbulent mixing shift competition for light between phytoplankton species. Ecology, 2004,85(11): 2960-2970.

[19］郭蔚华,李 楠,张 智等. 嘉陵江出口段三类水体蓝绿硅藻优势种变化机理. 生态环境学报,2009,18(1):51-56. 